\title{
Modulation of the Period of the Quasi-Biennial Oscillation by the Solar Cycle
}

\author{
LE KUAI AND Run-LiE SHIA \\ Division of Geological and Planetary Sciences, California Institute of Technology, Pasadena, California \\ XUN JIANG \\ Department of Earth and Atmospheric Sciences, University of Houston, Houston, Texas \\ KA KIT TUNG \\ Department of Applied Mathematics, University of Washington, Seattle, Washington \\ YUK L. YUNG \\ Division of Geological and Planetary Sciences, California Institute of Technology, Pasadena, California
}

(Manuscript received 22 September 2008, in final form 23 February 2009)

\begin{abstract}
The authors examine the mechanism of solar cycle modulation of the Quasi-Biennial Oscillation (QBO) period using the Two-and-a-Half-Dimensional Interactive Isentropic Research (THINAIR) model. Previous model results (using 2D and 3D models of varying complexity) have not convincingly established the proposed link of longer QBO periods during solar minima. Observational evidence for such a modulation is also controversial because it is only found during the period from the 1960s to the early 1990s, which is contaminated by volcanic aerosols. In the model, 200- and 400-yr runs without volcano influence can be obtained, long enough to establish some statistical robustness. Both in model and observed data, there is a strong synchronization of the QBO period with integer multiples of the semiannual oscillation (SAO) in the upper stratosphere. Under the current level of wave forcing, the period of the QBO jumps from one multiple of SAO to another and back so that it averages to 28 months, never settling down to a constant period. The "decadal" variability in the QBO period takes the form of "quantum" jumps; these, however, do not appear to follow the level of the solar flux in either the observation or the model using realistic quasi-periodic solar cycle (SC) forcing. To understand the solar modulation of the QBO period, the authors perform model runs with a range of perpetual solar forcing, either lower or higher than the current level. At the current level of solar forcing, the model QBO period consists of a distribution of four and five SAO periods, similar to the observed distribution. This distribution changes as solar forcing changes. For lower (higher) solar forcing, the distribution shifts to more (less) four SAO periods than five SAO periods. The record-averaged QBO period increases with the solar forcing. However, because this effect is rather weak and is detectable only with exaggerated forcing, the authors suggest that the previous result of the anticorrelation of the QBO period with the SC seen in short observational records reflects only a chance behavior of the QBO period, which naturally jumps in a nonstationary manner even if the solar forcing is held constant, and the correlation can change as the record gets longer.
\end{abstract}

\section{Introduction}

The quasi-biennial oscillation $(\mathrm{QBO})$ is an internal oscillation of the equatorial zonal wind in the strato-

\footnotetext{
Corresponding author address: Le Kuai, Planetary Sciences, California Institute of Technology, MC 150-21, 1200 E. California Blvd., Pasadena, CA 91125.

E-mail: kl@gps.caltech.edu
}

sphere involving wave-mean flow interactions (Holton and Lindzen 1972; Dunkerton 1997; Baldwin et al. 2001). There have been numerous observational studies of the QBO in the zonal wind, temperature, and ozone (e.g., Angell and Korshover 1970; Oltmans and London 1982; Hasebe 1983; Zawodny and McCormick 1991; Randel and Wu 1996; Pawson and Fiorino 1998). The period of the QBO averages about 28 months but is known to have interannual variations of a few months 
about the average. While it is not surprising for this phenomenon arising from wave-mean flow interaction to have a variable period, the possibility that it could be affected by external forcing such as the 11-yr solar cycle (SC) is intriguing.

Using radiosonde data from the Free University of Berlin (FUB) near the equator at $45 \mathrm{hPa}$ between 1956 and 1996, Salby and Callaghan (2000) found that the duration of the equatorial westerly phase $\mathrm{QBO}(\mathrm{w}-\mathrm{QBO})$ appears to vary with the $\mathrm{SC}$ and tends to be longer during the solar minima (SC-min). By comparison, the duration of the easterly phase of QBO (e-QBO) has little variability at that level but has a decadal variation above $30 \mathrm{hPa}$. Soukharev and Hood (2001) extended the work of Salby and Callaghan (2000) using composite mean analysis of a similar dataset but at 50-10 hPa from 1957 to 1999 . Their analysis also indicated that the duration of both QBO phases is longer during the SC-min. Pascoe et al. (2005) examined the ERA-40 dataset (Uppala et al. 2005) from 1958 to 2001 to study the solar modulation of the mean descent rate of the shear zone. They found that, on average, it requires two more months for the easterly shear zone to descend from 20 to $44 \mathrm{hPa}$ under the SC-min condition and that the w-QBO duration increases (decreases) under the SC-min [solar maxima (SC-max)] condition. This relation, however, broke down during the 1990s. Later, Hamilton (2002) and Fischer and Tung (2008) employed longer FUB datasets and both found opposite behavior in the 1950s, the late 1990s, and 2000s. Although there is anticorrelation (correlation coefficient $=-0.46$ ) between the w-QBO duration at $50 \mathrm{hPa}$ and the solar flux for the period from 1956 to 1996, Hamilton (2002) showed that the correlation coefficient is only -0.1 during the extended period from 1950 to 2001. Additionally, Fischer and Tung (2008), who applied the continuous wavelet transform to determine the $\mathrm{QBO}$ period at $50 \mathrm{hPa}$ for the longer record from 1953 to 2007, found that the correlation coefficient between the period of the QBO and a SC is practically zero. These later studies did not contradict the findings of the earlier authors. They merely pointed out that the behavior of the 1960s, 1970s, 1980s, and early 1990s were the opposite to that of the other decades before and after this period. A possible cause may be that the diabatic heating due to volcanic aerosols could lead to stalling of the downward propagation of the QBO (Dunkerton 1983). Fischer and Tung found that, in the recent two decades when no large volcanic eruptions occurred, the previous anticorrelation disappeared and reverted to a positive correlation, which was also found prior to the 1960s. A few more decades without volcanic interference would be needed to obtain a statistically significant correlation with the SC.
This complication can be circumvented in a modeling experiment.

An additional possibility considered here is that, with or without volcano aerosols in the stratosphere, the QBO period may respond to the solar flux in a nonstationary manner, with apparently random changes even without being perturbed by external forcing. The averaged effect on the QBO period by the solar cycle forcing is detectable only if the record is more than 100 years long. Although such a long record is not available in observation, model results for longer than $200 \mathrm{yr}$ can be generated to test this hypothesis.

\section{Relevant features in ERA-40 data}

There are two characteristics of the observed behavior of the QBO that are relevant to the present study but have been underemphasized by previous modeling and observational discussions: its synchronization with the semiannual oscillation (SAO) in the upper stratosphere and the apparently random "quantum" jumps of the QBO period by a multiple of the SAO period. A detailed description of these features in the 40-yr European Centre for Medium-Range Weather Forecasts ReAnalysis (ERA-40) data (Uppala et al. 2005) and an explanation of possible causes can be found in Kuai et al. (2009). Here we briefly summarize the observational results for the purpose of comparing with our model results. Figure 1 shows the equatorial zonal wind as a function of height (up to $1 \mathrm{hPa}$ ) and years using ERA-40 data. The upper two panels display the original monthly mean data. For the lower two panels, in the region of 1-3 hPa, where the $\mathrm{SAO}$ and QBO coexist, the QBO is removed by long-term averaging. Only a climatological seasonal cycle, which shows the SAO prominently without the QBO, is displayed in the $1-3-\mathrm{hPa}$ region. Below that the "raw" ERA-40 monthly zonal wind is again shown. A prominent SAO exists near the stratopause level and appears to be synchronized with the QBO below $5 \mathrm{hPa}$. That is, the w-QBO is initiated from a westerly phase of the SAO (w-SAO), and the next QBO period starts when another w-SAO, four or five SAO periods later, descends below $10 \mathrm{hPa}$. Therefore, the QBO period is always an integer multiple of the SAO period since the former always starts with the westerly descent of a SAO. In Fig. 2, we show the observed QBO period at $5 \mathrm{hPa}$ in units of a month, ignoring the false-start cases, when the SAO descends to $7 \mathrm{hPa}$ but, for some reason, fails to initiate a QBO below $10 \mathrm{hPa}$. It becomes immediately apparent that the QBO period varies in a nonstationary manner, taking quantum jumps from four SAO periods to five SAO periods. Such variations are not correlated or 

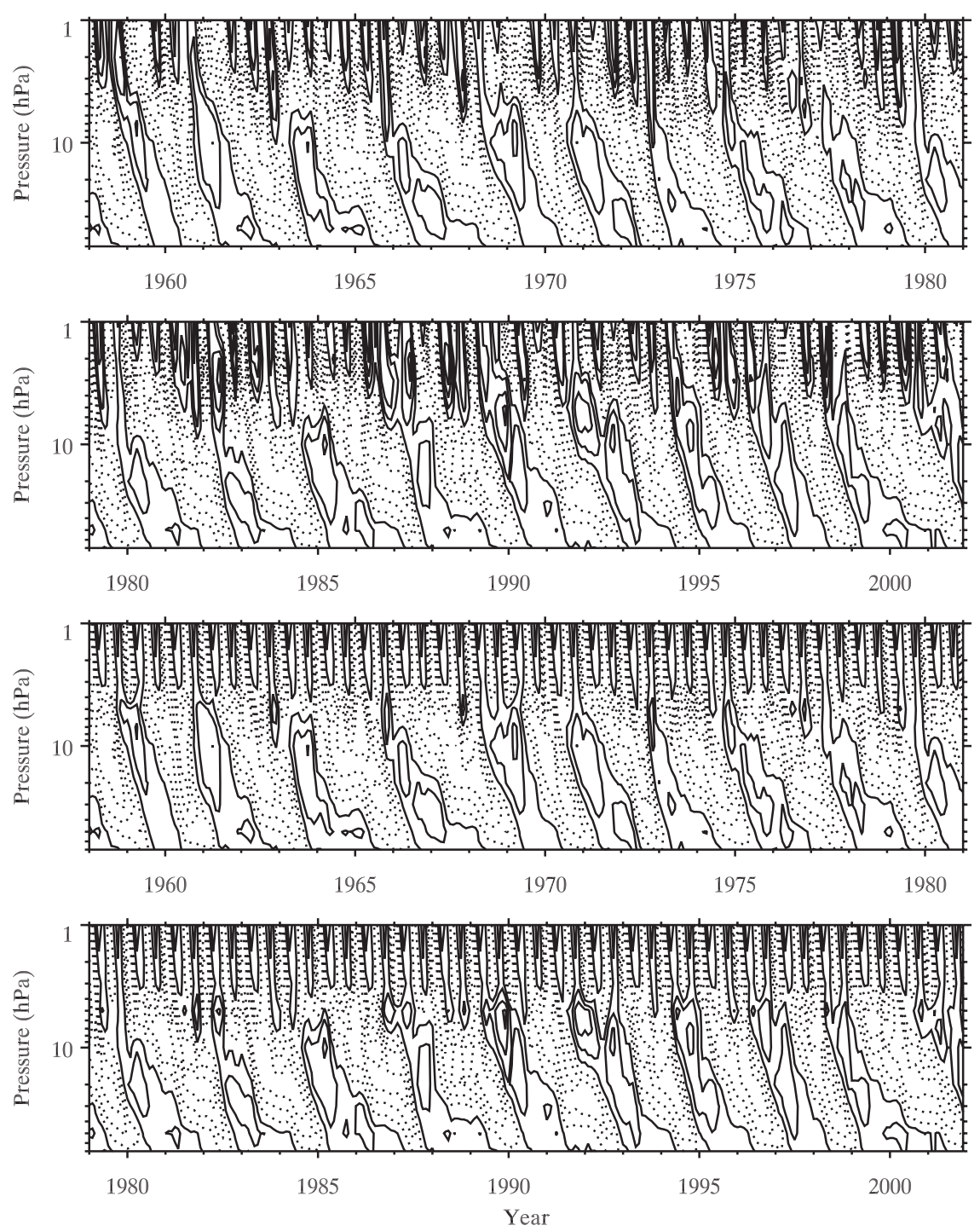

FIG. 1. Height-time cross section (top two panels) of the monthly-mean ERA-40 zonal wind. (bottom two panels) The zonal wind in the upper three levels $(1-3 \mathrm{hPa})$ is replaced by its seasonal climatology, which removes the QBO and shows the SAO more clearly.

anticorrelated with the SC [see the total solar irradiance (TSI) index plotted at the bottom of Fig. 2a]. Figure 2b is the histogram of the number of occurrences of the QBO period in months for the 45-yr ERA-40 data. It is seen that the QBO period in the upper stratosphere clusters around 24 and 30 months, corresponding to four or five SAO periods. The synchronization of the QBO period with an integer multiple of the SAO period is actually better than what one can casually infer from Fig. 2b if we express instead the QBO period in units of the SAO period. This is because the SAO period inferred from observation is not exactly six months because the SAO is imbedded in a variable background wind. It is seen that the reported mean period of 28 months for the QBO during this period of record is an average of $6 \mathrm{QBO}$ periods, each lasting 4 SAO periods (on average 24 months) and 12 QBO periods when it is $5 \mathrm{SAO}$ periods (on average 30 months). Figure $2 \mathrm{c}$ shows that there is very little vertical variation (usually within \pm 1 month between 1 and $40 \mathrm{hPa}$, with an occasional 2-month deviation) of the QBO period in the ERA-40 data (see also Fischer and Tung 2008).

\section{The model}

The Two-and-a-Half-Dimensional Interactive Isentropic Research (THINAIR) model is an isentropic 

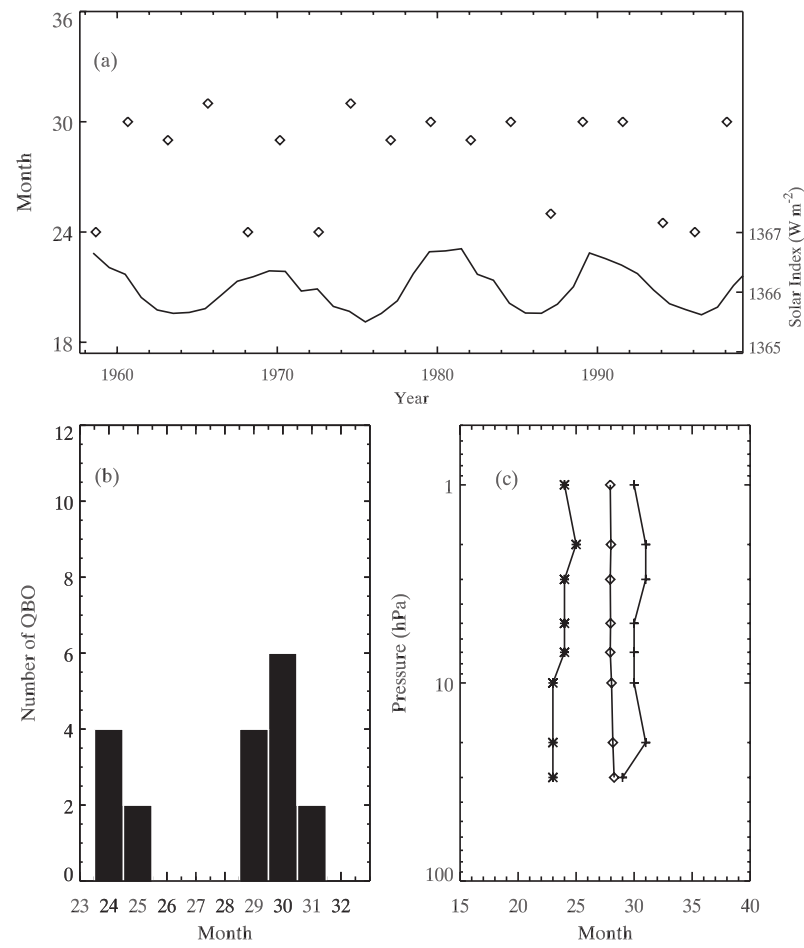

FIG. 2. The QBO period in ERA-40 data at $5 \mathrm{hPa}$ (a) in units of month (left scale). The solid curve at the bottom is the total solar irradiance $\left(\mathrm{W} \mathrm{m}^{-2}\right.$ ) (right scale). (b) Histogram of the QBO period, counting the number of occurrences of the QBO period in months. (c) The QBO period as a function of pressure level. Asterisks represent the QBO during 1997, plus signs represent the QBO during 1962, and diamonds represent the mean of all QBO periods in the ERA-40 record.

chemical-radiative-dynamical model. The model has zonally averaged radiation, chemistry, and dynamics and includes the three longest planetary waves, which are prescribed by observations at the tropopause level (Kinnersley and Harwood 1993). For this study, the planetary wave forcing at the tropopause is fixed at the 1979 year level derived from National Centers for Environmental Prediction (NCEP) reanalysis data (Kalnay et al. 1996; Kistler et al. 2001), annually periodic and repeated for all years. This choice reduces interannual variability of the planetary wave forcing so that the (weak) influence of the SC on the QBO can be studied. It removes tropospheric variability of planetary waves but retains stratospheric variability that is internally generated through wave-mean flow interaction and modulated by the SC. The model uses an isentropic vertical coordinate above $350 \mathrm{~K}$. Below $350 \mathrm{~K}$ a hybrid coordinate is used to avoid intersection of the coordinate layers with the ground. The version used in this study has 29 layers from the ground to $\sim 100 \mathrm{~km}$ for dynamics and 17 layers from the ground to $\sim 60 \mathrm{~km}$ for chemistry. The model has 19 meridional grid points evenly distributed from pole to pole. The QBO source term in the momentum equation uses parameterization of wave momentum fluxes from Kelvin, "anti-Kelvin" (to represent the Rossby-gravity wave), and gravity waves (Kinnersley and Pawson 1996). These momentum sources also partially force the SAO above the QBO. Upper Atmosphere Research Satellite/Solar U1traviolet Spectral Irradiance Monitor (UARS/SUSIM) spectral irradiance observation is used for the 11-yr SC. $U A R S /$ SUSIM data consists of the solar spectrum in 119-400 nm during 1991-2002, with 1-nm resolution. The monthly data are extended to 1947-2005 using F10.7-cm as a proxy (Jackman et al. 1996). The yearly averaged data are integrated to give photon fluxes in wavelength intervals appropriate for the THINAIR model. The performance of the model has been reported in the literature (Kinnersley and Pawson 1996). To avoid redoing the climatology of the model with the new $U A R S / S U S I M$ solar spectral forcing, we retain the mean SC forcing (SC-mean) in the original model and multiply it by the ratios (SC-max/SC-mean and SC-min/ SC-mean using the UARS/SUSIM data) to create the SC-max forcing and SC-min forcing. This procedure is also required because, although the relative variation over a SC is well measured by the UARS/SUSIM instrument, the mean is not calibrated accurately owing to possible long-term instrumental drifts.

\section{Model solar influence on QBO period}

\section{a. Time-varying $S C$ run}

Four-hundred-year runs are made using realistic, timevarying SC forcing for 1964-95 from UARS/SUSIM (extended as described above) and repeated thereafter. The SC-mean of this record is scaled to the SC-mean of the THINAIR model as described above. Even in this long run, the period of the QBO does not settle down to a fixed number but still executes apparently random jumps. The behavior of the QBO period is quite similar to that observed as discussed above. In particular, the QBO period jumps from four SAO periods to five SAO periods and back in a nonstationary manner. Figure 3 shows a height-time cross section of the zonal-mean zonal wind at the equator from the model for the $1 \times$ SC-vary case. Figure 4 shows the distribution of model QBO periods for the $1 \times \mathrm{SC}$-vary case from year 126 to year 172. The number of five SAO periods and four SAO periods are about equal in this 400 -yr run. However, in different smaller time segments of about 40-46 yr (20 QBOs) corresponding to the period of ERA-40 data, the distribution can shift. In some 

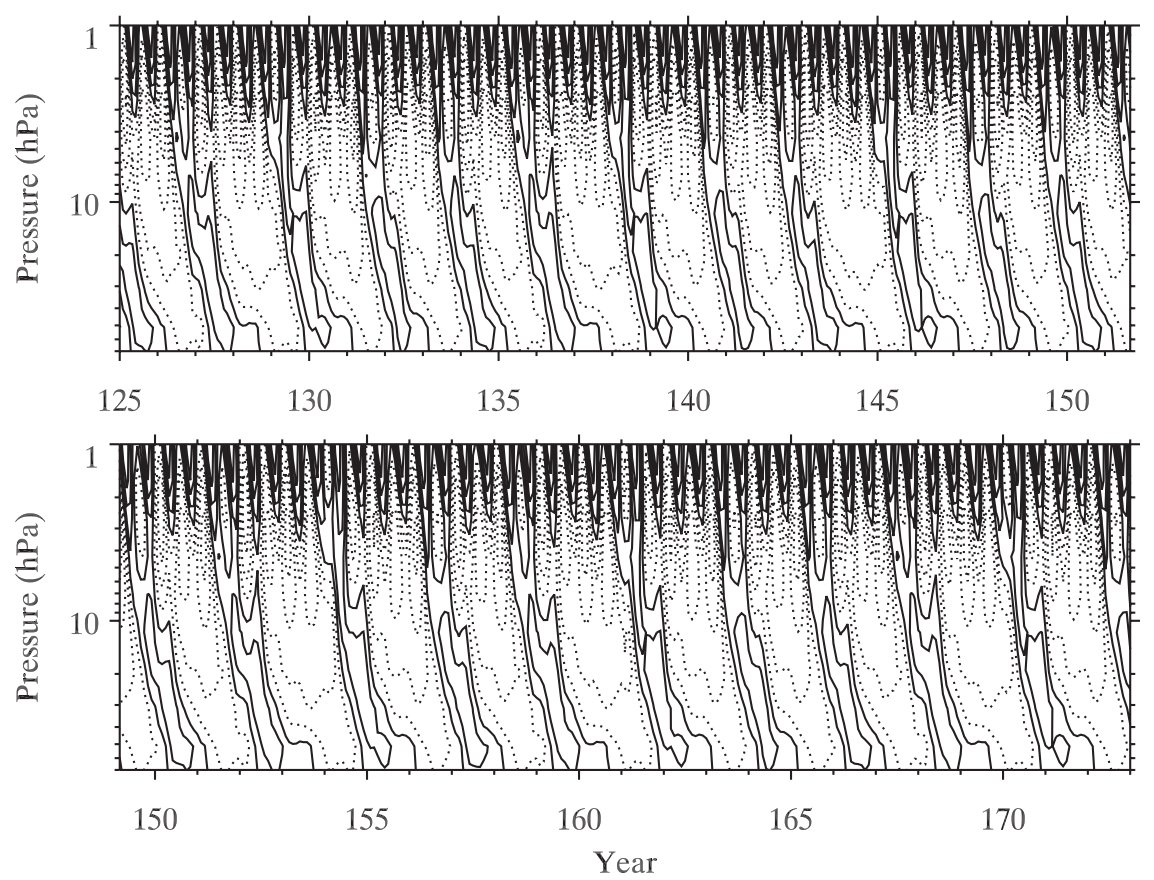

FIG. 3. Height-time cross section of zonal mean zonal wind for the $1 \times$ SC-vary case (top) from year 126 to year 151.5 and (bottom) from year 149.3 to year 172.8 .

segments, there are more five SAO periods than four SAO periods (Fig. 5c), as in the ERA-40 data. In other segments of about 40-46 yr, it can have an equal number of four SAO and five SAO (Fig. 5b) or more four SAO periods than five SAO periods (Fig. 5d). Therefore, we are not too concerned that the 400-yr model result has proportionally fewer five SAOs than in the ERA-40 data. Forty-five years of observations is probably too short to establish a robust statistics on the distribution; 200 years are needed. The results presented below for perpetual solar forcing runs are from the 200-yr runs.

The correlation of the QBO period with the TSI index is small in the model 200-yr run. The correlation coefficient is 0.172 , consistent with that in the ERA-40 data of 0.05 ; neither is statistically significant. This result applies to the entire stratosphere since the QBO period is almost constant with height in both model and ERA-40 data, within an accuracy of 1-2 months (Fischer and Tung 2008).

\section{b. Perpetual solar forcing runs}

Additionally, we perform 200-yr constant solar-cycle forcing experiments in our model to answer the question of whether the nonstationary nature of the QBO period is because the solar cycle forcing is time varying. It should be pointed out that we still have the seasonal cycle in the "perpetual" solar runs. Figure $6 c$ is similar to Fig. 3 except for the perpetual solar cycle mean forcing, in the 200-yr runs. There are no qualitative differences in the results between the perpetual solar forcing run and the variable solar cycle forcing run. In particular, the QBO period still jumps irregularly from four SAO to five SAO periods and back. We, therefore, conclude that the nonstationary nature of the QBO period is not because the solar-cycle forcing is time varying.

\section{c. Exaggerated, perpetual solar cycle forcing}

In these experiments, the SC-mean forcing in the model is multiplied by the ratio

$$
\frac{\mathrm{SC}_{\text {mean }}+n \Delta}{\mathrm{SC}_{\text {mean }}}
$$

where $\Delta=\left(\mathrm{SC}_{\max }-\mathrm{SC}_{\min }\right) / 2$. Figure $6 \mathrm{a}$ is for the perpetual $15 \times \mathrm{SC}$-min condition $(n=-15$ in the above definition). At this low solar forcing, the QBO period is mostly at four SAO periods. At the slightly higher, but still low, $10 \times$ SC-min forcing $(n=-10)$, the QBO period consists mostly of four SAO periods, with an occasional five SAO period (see Fig. 6b). Figure 6d shows the result for the high solar forcing, at $10 \times \mathrm{SC}$ $\max (n=10)$, case. There are now more five SAO than four SAO periods. Figure 6e shows the case for still higher SC forcing, at $15 \times$ SC-max $(n=15)$. The distribution shifts toward even more five SAO 

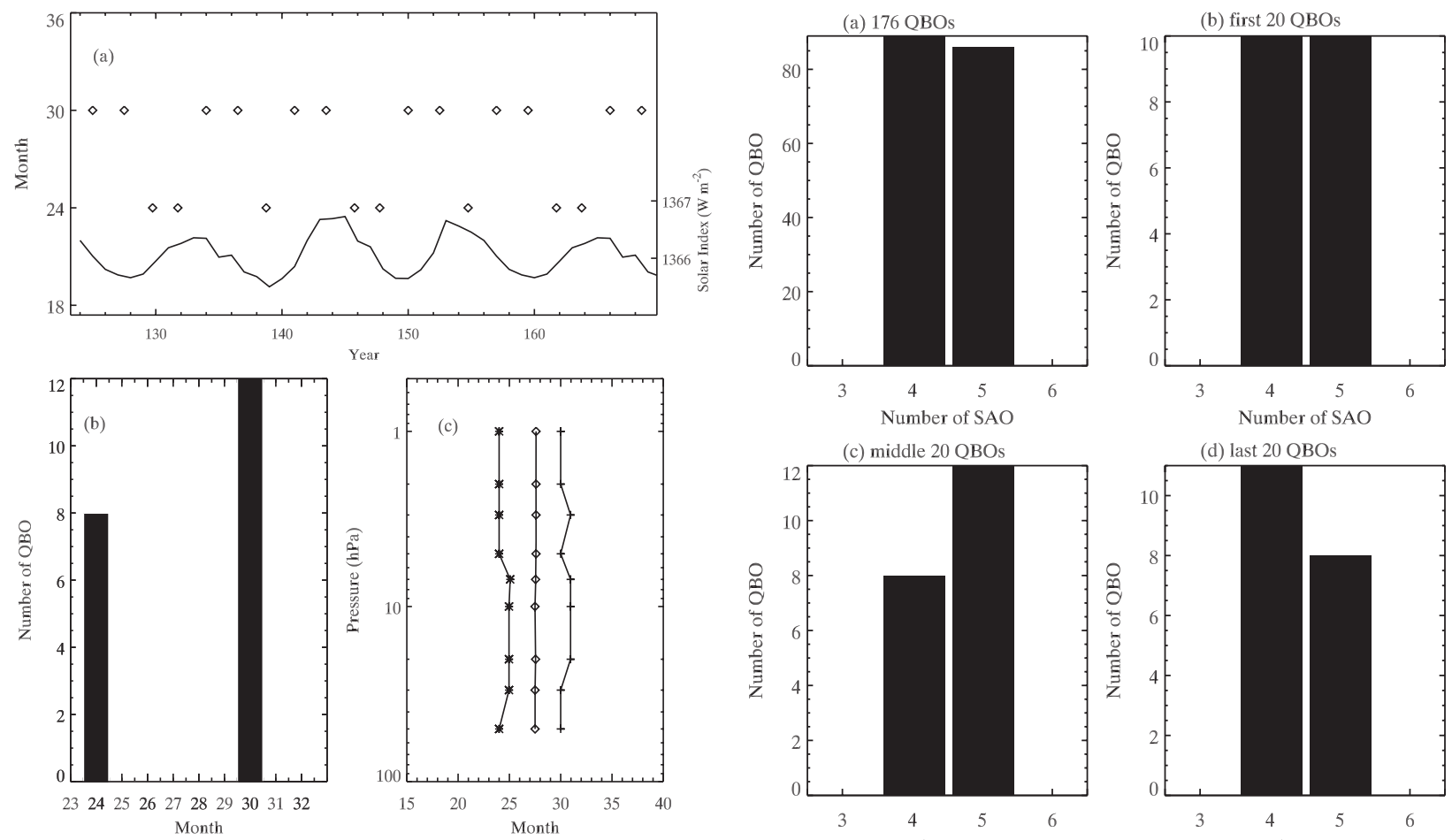

FIG. 4. As in Fig. 2 but from model results for the $1 \times$ SC-vary case. The solid curve is the solar index as in Fig. 2 but repeating the data from 1964 to 1995 to cover 400 yr. Forty-six years out of the 400-yr run, from year 126 to year 172, are used for the purpose of comparing with the ERA-40 period. In (c) the asterisk (plus) represents the QBO during year 162 (128); the diamond represents the mean QBO periods during the $46 \mathrm{yr}$.

periods. The histograms for the QBO periods for these five cases are shown in Fig. 7, along with an additional case of $5 \times \operatorname{SC}$-max $(n=5)$.

In summary, we find that, even with perpetual solar forcing, the nonstationary jumps in QBO period continue with a tendency to jump to longer periods in response to higher solar forcing. Thus, there appears to be some modulation of the QBO period by the SC, but such modulation is only apparent at exaggerated solar forcing. Furthermore, the correlation of solar forcing magnitude and the average QBO period is positive, in contrast to the implication by some previous authors that the QBO period is longer during solar minima. In the realistic case of periodic solar-cycle forcing, the instantaneous correlation of the QBO period with the SC is not statistically significant, consistent with the ERA-40 result.

\section{Partition of the QBO period into westerly and easterly durations}

In Fig. 8 we plot the QBO period as a function of the solar index in units of solar flux (one unit represents
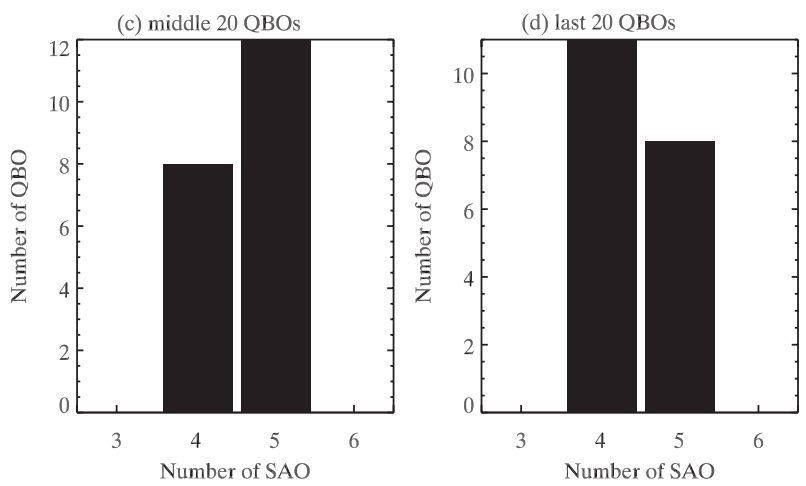

FIG. 5. Histogram of the QBO period, number of occurrences (left column) for the four SAO and (right column) for the five SAO period (a) over the 400-yr period and (b)-(d) different smaller time segments of 20 QBO periods, about 40-46 yr.

one-half of the difference of solar fluxes between the SC-max and SC-min) over the pressure range from 10 to $80 \mathrm{hPa}$ in the model. This establishes that the mean period of the QBO, including its easterly and westerly durations, generally increases as the solar flux increases, contrary to the finding of previous authors that the period reaches a maximum during solar minima. In this model there is little variation of the mean (and also individual) QBO period with height (Fig. 8a has lines for seven levels from 7 to $80 \mathrm{hPa}$, overlapping and indistinguishable from each other). Above $30 \mathrm{hPa}$ it is the easterly duration that varies with solar flux (Figs. 8b-d), while below $50 \mathrm{hPa}$ it is the westerly duration that varies slightly more with solar flux (Fig. 8e), consistent with the observational result of Fischer and Tung (2008). The occasional stalling of the easterlies at $30 \mathrm{hPa}$ and the prolonged westerly duration at $50 \mathrm{hPa}$ are not seen clearly in these figures because only the average is shown, but these cases can be seen in the height-time diagrams in Fig. 6.

In this model, stalling of the easterly descent tends to occur in some years at around $40 \mathrm{hPa}$. Below that level the westerly duration becomes longer in these years. 

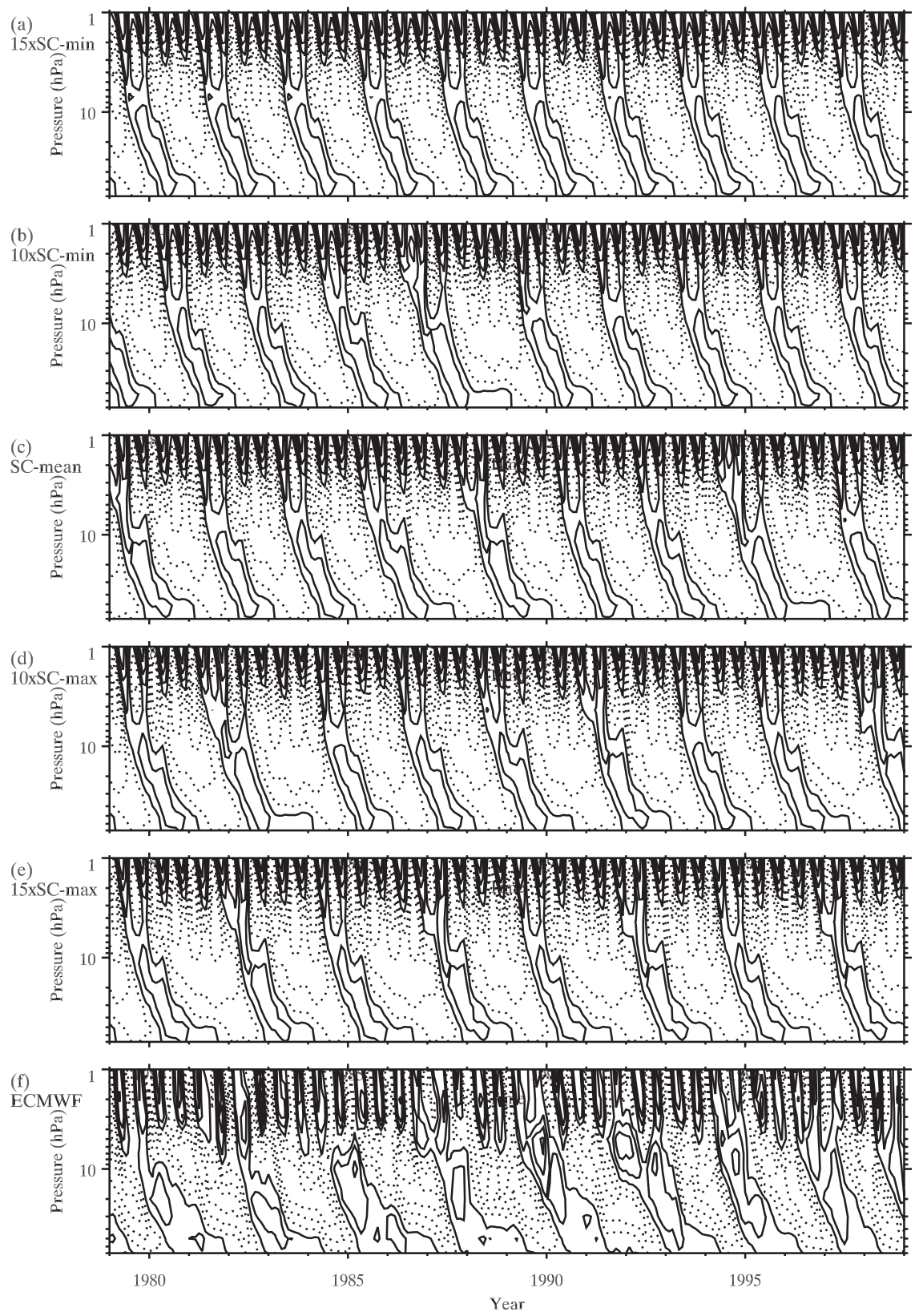

FIG. 6. Time-height section of the equatorial monthly-mean zonal wind component $\left(\mathrm{m} \mathrm{s}^{-1}\right)$ from the THINAIR model simulation for the (a) $15 \times$ SC-min, (b) $10 \times$ SC-min, (c) SC-mean, (d) $10 \times$ SC-max, and (e) $15 \times$ SC-max perpetual condition; (f) ERA-40 observational data. The individual QBO period is synchronized with the SAO near the stratopause.

The westerly duration lasts between one and two years. As the solar cycle flux increases, the westerly duration becomes longer. Therefore, it is the average westerly duration near $50 \mathrm{hPa}$ that is correlated with the solar flux, whereas the easterly duration there shows much smaller variability from one QBO period to the next. Since the next westerly phase is not initiated at the upper stratosphere until the westerly region in the lower stratosphere wanes-due to filtering of the westerly waves by the lower stratospheric westerly region-the easterly phase above $30 \mathrm{hPa}$ is correspondingly lengthened, and its mean value is correlated with the solar flux. This is consistent with the finding of Salby and Callaghan (2000), except that here the correlation with the solar flux is positive instead of the anticorrelation found by them. 

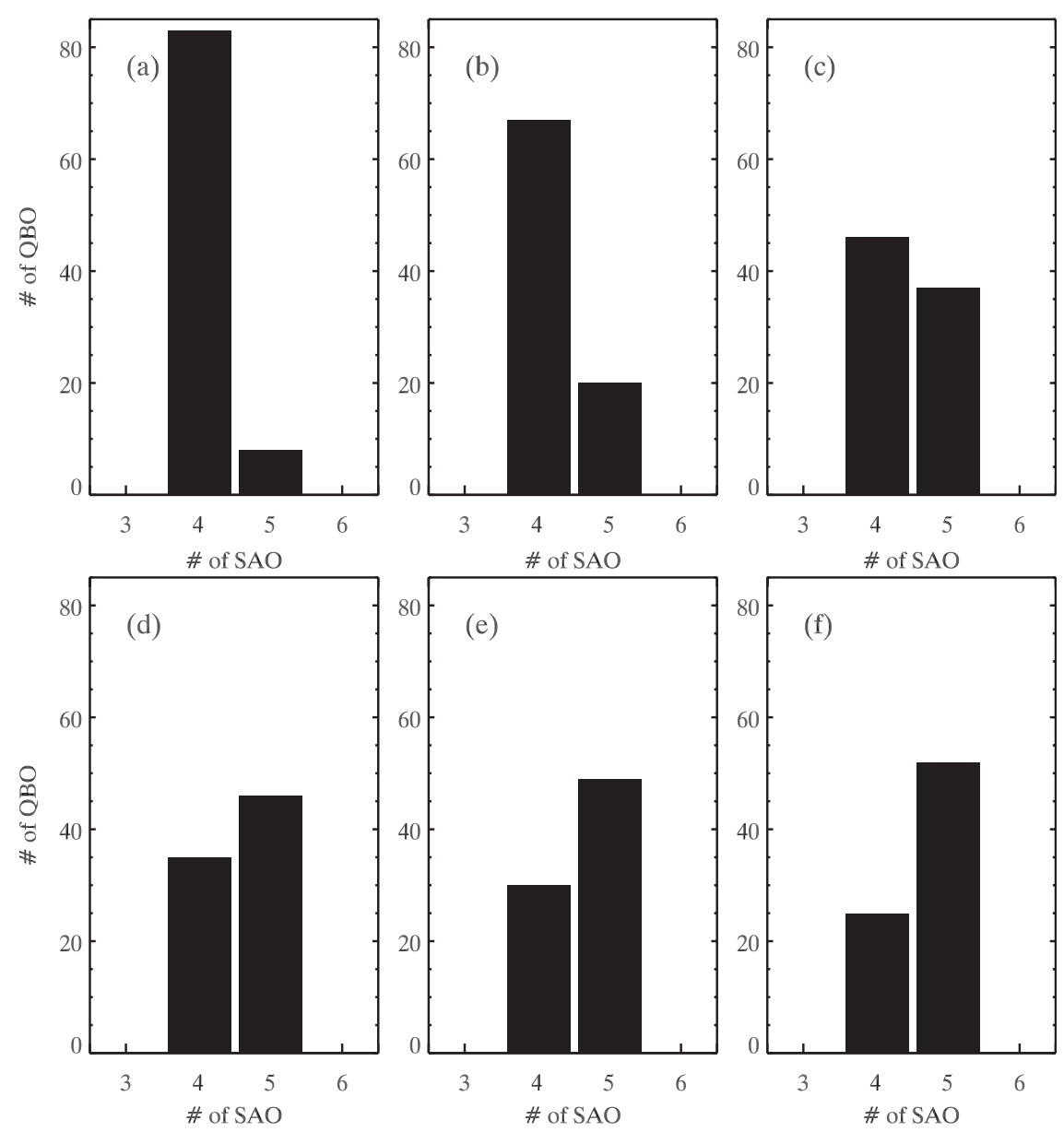

FIG. 7. Histogram of the QBO period in model runs for various perpetual solar cycle forcing with the resulting averaged QBO period (in parentheses): (a) $15 \times \mathrm{SC}$-min (24.64 months); (b) $10 \times$ SC-min (25.66 months); (c) SC-mean (26.67 months); (d) $5 \times$ SC-max (27.20 months); (e) $10 \times$ SC-max (28.43 months); and (f) $15 \times$ SC-max $(29.04$ months).

\section{Possible mechanisms for solar modulation of the QBO period}

As mentioned above, one unique feature of the QBO variability is the apparently random quantum jumps in its period from one SAO multiple to another. This is found in observations and in this model with and without a variable SC forcing. An explanation for this behavior is given in Kuai et al. (2009), as a result of the QBO trying to satisfy two often incompatible factors in determining its period: its period as determined internally by the wave forcing amplitude and the wave speed (see Plumb 1977), and that its period has to be integer multiples of the SAO period. The latter is not an absolute requirement, but the westerly phase of the SAO initiates (and thus seeds) the westerly phase of the QBO in the upper equatorial stratosphere, where it is generally easterly without the SAO. The first factor deter- mines that the period should be approximately 28 months, which is intermediate between four SAO and five SAO periods. It achieves an averaged period of 28 months by jumping between four SAO and five SAO periods. It does so even if the solar forcing is held constant. These nonstationary jumps, of about six months from one period to another, account for most of the variability of the QBO period and can probably account for the contradictory findings of correlation and anticorrelation with the SC depending on which segment of record one examines.

Nevertheless, SC influence on the mean QBO period does exist. These effects are weak, but are detectable in the model, and appear to be opposite to what was previously proposed. We offer an explanation below.

Camp and Tung (2007) found that the polar stratosphere is warmer during SC-max because of the higher frequency of sudden warmings (Labitzk 1982) and 

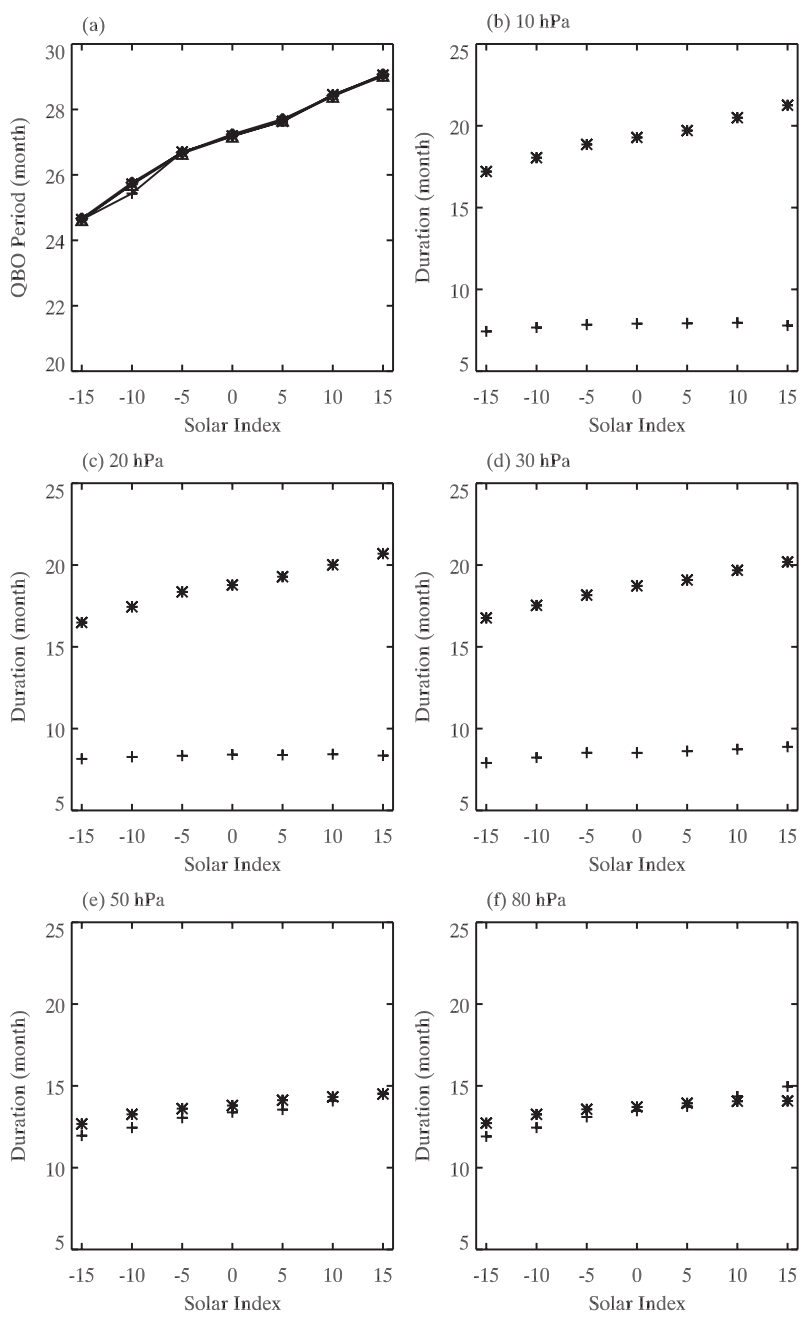

FIG. 8. The QBO period, averaged over the model run, as a function of the solar forcing (in units of $\Delta$ ) at pressure levels (a) from 10 to $80 \mathrm{hPa}$ and at (b) $10 \mathrm{hPa}$, (c) $20 \mathrm{hPa}$, (d) $30 \mathrm{hPa}$, (e) 50 $\mathrm{hPa}$, and (f) $80 \mathrm{hPa}$; overlapping lines show not much vertical variation; easterly duration is shown with an asterisk and westerly duration with plus sign.

therefore the Brewer-Dobson circulation is more downward in mid to high latitudes (Cordero and Nathan 2005). This could remotely force a stronger compensating upwelling branch of the Brewer-Dobson circulation over the equator, which then slows the descent of the QBO shear zone and extends the QBO period. Because the QBO-induced secondary circulation itself is also upward for the easterly phase at the equator, the $\mathrm{e}-\mathrm{QBO}$ is more vulnerable to slowing and eventual stalling, which usually occurs near $30 \mathrm{hPa}$ (Plumb and Bell 1982a,b). Below the stalling level, the westerly phase persists without being replaced by the descending easterlies, leading to a longer westerly duration. In this model there is no local heating due to volcanic aerosols, so the anomalous upwelling over the equator is remotely forced by the breaking of planetary waves in the extratropics. This is the so-called polar route (Pascoe et al. 2005).

This feature of occasional stalling of the easterlies and the prolonged westerly duration below in the lower stratosphere is absent in the 2D model of Mayr et al. (2003), which does not have planetary waves that interact with the mean flow altered by solar cycle forcing. Consequently in their model the descent of the easterlies and westerlies is more uniform than here and in the observed data. The prolonged $\mathrm{w}-\mathrm{QBO}$ in the lower stratosphere is an important feature of the observed decadal variation of the QBO period because it delays the onset of the next westerly descent into the stratosphere by filtering out the westerly waves. In the absence of westerly wave momentum deposition, the easterly duration is lengthened in the upper stratosphere. In the observational result of Fischer and Tung (2008), the decadal variation of the easterly duration at $15 \mathrm{hPa}$ is tied to that of the westerly duration at $50 \mathrm{hPa}$. This feature is also seen in this model.

A second mechanism is the so-called equatorial route of local radiative heating by the increased solar flux in SC-max as compared to the SC-min. In this model the UV radiation of the SC forcing interacts with ozone most strongly in the stratopause region, and the resulting diabatic heating affects the propagation of equatorial waves in the upper stratosphere and affects the wave forcing of the QBO. This solar perturbation serves to "kick" the QBO period from one SAO multiple into another-higher (on average)-multiple. To test this hypothesis, we make another run by switching off the SC-ozone feedback. Ozone in the model is then not allowed to change as SC changes, but other interactions with dynamics are still allowed. When the ozone concentration is fixed, the mean QBO period changes very little with solar flux, even for up to $15 \times \mathrm{SC}$-max. This experiment suggests that the small positive dependence of QBO period on the strength of the solar flux that we see in the model is mostly due to this "equatorial route." Although much more work needs to be done to fully understand this mechanism, we do not believe it is worth the effort at this time given how small an effect it has on the QBO period under realistic levels of solar forcing.

Another mechanism for solar influence on the period of QBO was proposed by Cordero and Nathan (2005), who employed a model simulation to show that the QBO circulation is slightly stronger (weaker) during the SC-max (SC-min), resulting in a shorter (longer) QBO period arising from wave-ozone feedback. They argued that this leads to the required diabatic heating that slows 
down the descent rate of the equatorial QBO. This wave-ozone feedback is not included in our model.

In summary, we have discussed two mechanisms of how a change in solar flux affects the period of the QBO. Both are weak under the current SC forcingexplaining perhaps about one to two months of the variability - but can nevertheless account for the tendency of positive correlation of the mean QBO period with the SC in models: 1) through a change in the strength of the Brewer-Dobson circulation by its effect on planetary waves and 2) by local heating change in the upper stratosphere. The first mechanism is a remote mechanism that is absent in 2D models without interannual change in planetary wave propagation and dissipation. The second mechanism is local and affects the magnitude of the radiative heating perturbation that alters the wave forcing of the QBO. This effect is absent in models without ozone photochemistry. This latter mechanism responds to increasing solar forcing by changing the distribution of its period to fewer four SAO periods and more five SAO periods. The first mechanism, as previously suggested, affects mainly the partition of the QBO into its easterly and westerly phases. Its effect on the QBO period is about one month or less. The second mechanism is effective only when the SC forcing is magnified 5-10 times.

\section{Conclusions}

It is well known that the polar stratosphere in winter is significantly more perturbed when the equatorial QBO is easterly than when it is westerly (Holton and Tan 1980, 1982; Baldwin et al. 2001). A mechanism that can affect the period of the equatorial QBO, by altering the timing of the phase of the QBO relative to the polar winter, will therefore have a significant impact on the circulation of the entire stratosphere. The 11-yr SC has often been cited as being able to modulate the equatorial QBO period, especially its westerly duration in the lower stratosphere. Salby and Callaghan (2000), Soukharev and Hood (2001), and Pascoe et al. (2005) found that the duration of the $\mathrm{w}-\mathrm{QBO}$ in the lower stratosphere is lengthened during solar minima based on observations. While confirming these results, Hamilton (2002) and Fischer and Tung (2008) found with longer datasets that perhaps the opposite may hold during other decades, which coincidentally did not have volcanic aerosol contamination. The record is not long enough for us to establish the behavior of the solar cycle modulation of the QBO period in a clean stratosphere, although it is not clear if the volcanoes were the culprit. In the present model in which there is no volcanic influence and long runs are possible, we find that the main
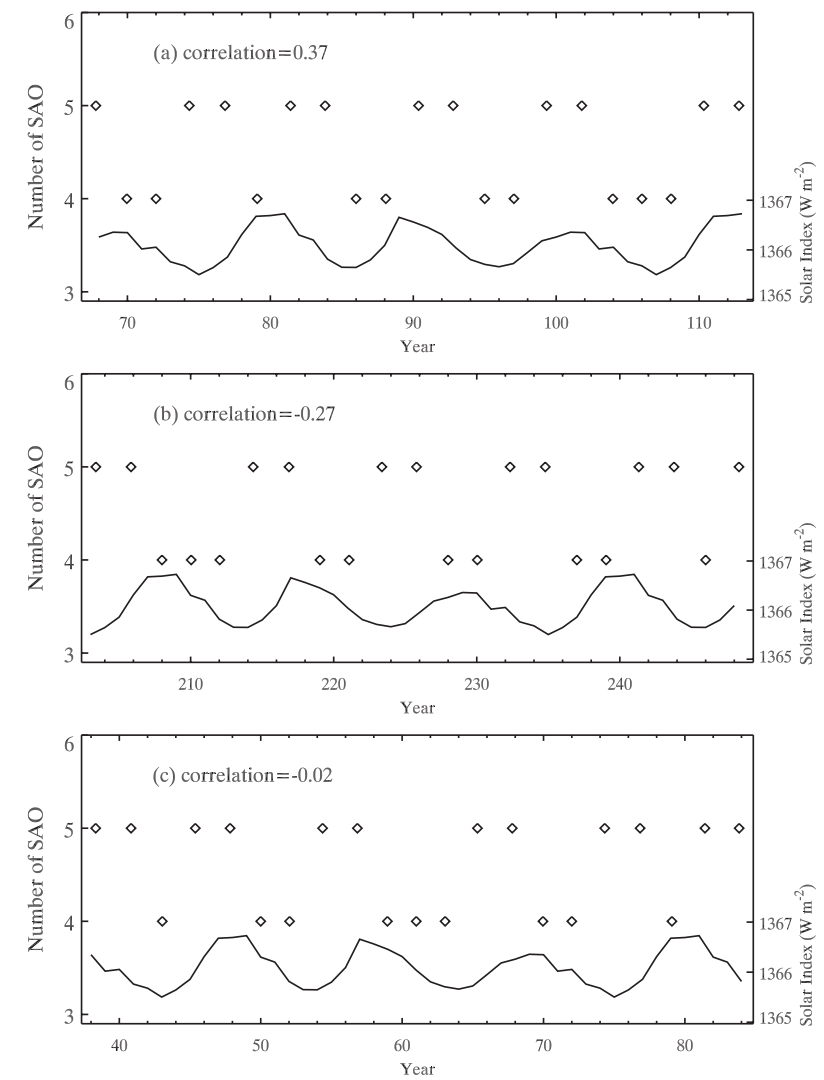

FIG. 9. The QBO period as a function of years in the 400-yr periodic solar cycle run. The TSI index is shown in solid line with the right-hand scale. The various panels are segments of the run of 40-46 yr each (about 20 QBOs). The correlation of the QBO period with the TSI index is marked for each period.

variability of the $\mathrm{QBO}$ period is not related to the $\mathrm{SC}$, but is an intrinsic property of the QBO itself. "Quantum" jumps of about six months between QBO periods occur in an apparently random fashion even when the variability in the solar forcing is suppressed in the model. In shorter segments of the record, such variability can give the appearance of instantaneous correlation or anticorrelation with the SC. Examples are shown in Fig. 9: both positive and negative instantaneous correlations with the SC can be found in short segments with durations comparable to those used in previous observational studies, whereas there is no statistically significant correlation of QBO period with the SC in the long records of 200 or even 400 model years of periodic forcing.

When the nonstationary variability of the QBO period is averaged out in a long enough run $(200 \mathrm{yr})$, there is a statistically significant positive correlation of the averaged QBO period with the solar forcing: the QBO period is lengthened during solar maxima, and the increase in period is proportional to the solar cycle 
forcing. This effect is weak and can be overwhelmed by the nonstationary behavior in shorter records. This finding may reconcile the contradictory findings of Salby and Callaghan (2000), Hamilton (2002), and Fischer and Tung (2008), using observations from FUB of various lengths that show either anticorrelation or no correlation of the QBO period with the SC.

Acknowledgments. This work was supported in part by NASA Grants NAG1-1806 and NNG04GN02G to the California Institute of Technology. K. K. Tung's research was supported by NSF Grants ATM 0332364 and ATM 0808375 to the University of Washington. We thank A. Ruzmaikin and J. Feynman for their useful discussions. We also acknowledge help in improving the paper from M. C. Liang, N. Heavens, X. Guo, A. Soto, T. Lee, X. Zhang, P. S. Jiang, Y. C. Chen, D. Yang, and C. D. Camp.

\section{REFERENCES}

Angell, J. K., and J. Korshover, 1970: Quasi-biennial, annual, and semiannual zonal wind and temperature harmonic amplitudes and phases in the stratosphere and low mesosphere of the Northern Hemisphere. J. Geophys. Res., 75 (3), 543-550.

Baldwin, M. P., and Coauthors, 2001: The quasi-biennial oscillation. Rev. Geophys., 39, 179-229.

Camp, C. D., and K. K. Tung, 2007: The influence of the solar cycle and QBO on the late-winter stratospheric polar vortex. J. Atmos. Sci., 64, 1267-1283.

Cordero, E. C., and T. R. Nathan, 2005: A new pathway for communicating the 11-year solar cycle signal to the QBO. Geophys. Res. Lett., 32, L18805, doi:10.1029/2005GL023696.

Dunkerton, T. J., 1983: Modification of stratospheric circulation by race constituent changes? J. Geophys. Res., 88, 10 831-10 836.

- 1997: The role of gravity waves in the quasi-biennial oscillation. J. Geophys. Res., 102 (D22), 26 053-26 076.

Fischer, P., and K. K. Tung, 2008: A reexamination of the QBO period modulation by the solar cycle. J. Geophys. Res., 113, D07114, doi:10.1029/2007JD008983.

Hamilton, K., 2002: On the quasi-decadal modulation of the stratospheric QBO period. J. Climate, 15, 2562-2565.

Hasebe, F., 1983: Interannual variations of global total ozone revealed from Nimbus 4 BUV and ground-based observations. J. Geophys. Res., 88 (C11), 6819-6834.

Holton, J. R., and R. S. Lindzen, 1972: An updated theory for the quasi-biennial cycle of the tropical stratosphere. J. Atmos. Sci., 29, 1076-1080.

— biennial oscillation on the global circulation at $50 \mathrm{mb}$. J. Atmos. Sci., 37, 2200-2208.

— ern Hemisphere lower stratosphere. J. Meteor. Soc. Japan, 60, 140-148.
Jackman, C., E. L. Fleming, S. Chandra, D. B. Considine, and J. E. Rosenfield, 1996: Past, present, and future modeled ozone trends with comparisons to observed trends. J. Geophys. Res., 101 (D22), 28 753-28 767.

Kalnay, E., and Coauthors, 1996: The NCEP/NCAR 40-Year Reanalysis Project. Bull. Amer. Meteor. Soc., 77, 437-471.

Kinnersley, J. S., and R. S. Harwood, 1993: An isentropic twodimensional model with an interactive parameterization of dynamical and chemical planetary-wave fluxes. Quart. J. Roy. Meteor. Soc., 119, 1167-1193.

, and S. Pawson, 1996: The descent rates of the shear zones of the equatorial QBO. J. Atmos. Sci., 53, 1937-1949.

Kistler, R., and Coauthors, 2001: The NCEP-NCAR 50-year reanalysis: Monthly means CD-ROM and documentation. Bull. Amer. Meteor. Soc., 82, 247-267.

Kuai, L., R. L. Shia, X. Jiang, K. K. Tung, and Y. L. Yung, 2009: Nonstationary synchronization of equatorial QBO with SAO in observations and a model. J. Atmos. Sci., 66, 1654-1664.

Labitzk, K., 1982: On the interannual variability of the middle stratosphere during the northern winters. J. Meteor. Soc. Japan, 60, 124-139.

Mayr, H. G., J. G. Mengel, D. P. Drob, H. S. Porter, and K. L. Chan, 2003: Modeling studies with QBO: II. Solar cycle effect. J. Atmos. Sol.-Terr. Phys., 65, 901-916.

Oltmans, S. J., and J. London, 1982: The quasi-biennial oscillation in atmospheric ozone. J. Geophys. Res., 87 (C11), 8981-8989.

Pascoe, C. L., L. J. Gray, S. A. Crooks, M. N. Juckes, and M. P. Baldwin, 2005: The quasi-biennial oscillation: Analysis using ERA-40 data. J. Geophys. Res., 110, D08105, doi:10.1029/ 2004JD004941.

Pawson, S., and M. Fiorino, 1998: A comparison of reanalyses in the tropical stratosphere. Part 2: The quasi-biennial oscillation. Climate Dyn., 14, 645-658.

Plumb, R. A., 1977: Interaction of two internal waves with mean flow: Implications for theory of quasi-biennial oscillation. J. Atmos. Sci., 34, 1847-1858.

_ , and R. C. Bell, 1982a: Equatorial waves in steady zonal shear flow. Quart. J. Roy. Meteor. Soc., 108, 313-334.

$\longrightarrow$, and - 1982b: A model of the quasi-biennial oscillation on an equatorial beta-plane. Quart. J. Roy. Meteor. Soc., 108, 335-352.

Randel, W. J., and F. Wu, 1996: Isolation of the ozone QBO in SAGE II data by singular-value decomposition. J. Atmos. Sci., 53, 2546-2559.

Salby, M. L., and P. F. Callaghan, 2000: Connection between the solar cycle and the QBO: The missing link. J. Climate, 13, 2652-2662.

Soukharev, B. E., and L. L. Hood, 2001: Possible solar modulation of the equatorial quasi-biennial oscillation: Additional statistical evidence. J. Geophys. Res., 106 (D14), 14 855-14 868.

Uppala, S. M., and Coauthors, 2005: The ERA-40 Re-Analysis. Quart. J. Roy. Meteor. Soc., 131, 2961-3012.

Zawodny, J. M., and M. P. McCormick, 1991: Stratospheric Aerosol and Gas Experiment II measurements of the quasibiennial oscillations in ozone and nitrogen dioxide. J. Geophys. Res., 96 (D5), 9371-9377. 